\title{
EXPERIMENTAL PETROLOGY AT HIGH PRESSURES AND TEMPERATURES
}

by

Peter J. Wyllie

In 1969, when it was first suggested that a Subcommission on Experimental Petrology at High Pressures and Temperatures be established, the reaction from the IUGS Petrology Commission was favourable. The Subcommission, with six members and Professor Werner Schreyer as Chairman, became a Commission (CEPHT) in 1972. Peter Wyllie, current Chairman of this Commission, describes the evolution of experimental petrology, its application to geophysical, petrological and geological processes, as well as what lies ahead in future exploration of this "research frontier".

\section{The Commission}

During the International Upper Mantle Project of the 1960 's, it became clear that the interests of geophysicists and geochemists overlap within the phase diagrams produced by experimental petrologists. This was especially so when research was extended to include the physical properties of materials in various phase fields and associated phase transitions. Whereas petrologists had been concerned mainly with the recrystallization of metamorphic rocks, and the crystallization and differentiation of magmas, development of the concept of plate tectonics focussed their attention on the underlying causes of abnormal temperatures (high or low) associated with metamorphism, the nature of source materials at depth, and thermal perturbations causing the generation of magmas. Geophysics had become a starting point for many aspects of petrogenesis, and geophysicists needed the data of petrology and geochemistry to characterize the earth materials whose properties they measured. The theoretical approaches of thermodynamics and geophysical fluid dynamics were being applied with greater success to the problems of petrology. These considerations led to the establishment of the IUGS Commission on Experimental Petrology at High Pressures and Temperatures (CEPHT).

Experimental petrology is concerned with investigation in the laboratory of mineral equilibria and dynamic processes in rock and mineral systems under controlled physical conditions. One aim of the Commission is to increase international communication and cooperation among specialists in this field. Even more important, the Commission wishes to promote and encourage interaction between the experimental petrologists and earth scientists of other specializations.

The earth is a chemical system responding to changes in pressure and temperature which occur to packages of rock material as they move vertically or horizontally within the earth. The response of the chemical system causes the boundary between the solid earth and its fluid envelopes to move up or down. Accordingly, members of the Commission argue that it is important for all earth scientists to become aware of the potential of experimental petrology. Several Symposia have been organized at International Meetings to elucidate the applications of experimental petrology to various topics. When the Inter-Union Commission on Geodynamics (ICG) was established as a joint ICSU enterprise of IUGS and the International Union of Geodesy and Geophysics (IUGG), parallel interests led to fruitful cooperation between CEPHT and the ICG Working Groups.

\section{Development of Experimental Petrology}

Experimental petrology was developed at the Geophysical Laboratory, Carnegie Institute, Washington, D.C., during the first half of this century. The early approaches are well illustrated by the 1928 book of N.L. Bowen, The Evolution of the Igneous Rocks, which will be recognized officially by two "memorial volumes" to be published in 1978. Bowen made remarkable use of phase diagrams, both experimentally determined and deduced. In his Preface, he wrote:

"It was my hope that, before any thing of the kind
here offered was written, all of the diagrams it
would be necessary to use would be determined
diagrams. Yet I offer no apology for the use of
deduced diagrams where this is still
necessary.... Attack with their aid may be
regarded as a skirmishing which feels out the
strength and the weakness of our adversaries, the
rocks, and thus lays a necessary foundation for a
more serious campaign of experimental attack,
concentrated upon these points where progress is
most likely to be made."

In his introduction to the 1956 reprint, J.F. Schairer commented that Bowen's (1928) book had been influential mainly because "it showed how a knowledge of the equilibrium relations to silicate systems, in conjunction with field observations on the rocks and studies of the rockforming minerals, helped to elucidate the nature and mechanism of the processes involved in rock origins".

The number of determined phase diagrams has increased greatly since 1928, due in large part to scientists who learned the trade at the Geophysical Laboratory and subsequently established their own laboratories. Most experimental results were obtained at 1 atmosphere pressure until 1950, after which a simple pressure-vessel designed by O.F. Tuttle came into general use. This permitted, for the first time, the study of reactions in the presence of volatile components at crustal pressures and temperatures and under routine conditions that could be managed by students. The fugitive components of crustal processes could be trapped, and their effects determined.

For the reproduction of pressures and temperatures in the earth's mantle, more elaborate apparatus is needed. The single-stage piston-cylinder apparatus, designed by F.R. Boyd and J.L. England and developed also by G.C. Kennedy, has been widely adopted since 1960, and there are now many 
phase diagrams determined at pressures corresponding to depths of $100 \mathrm{~km}$. Many more are needed, however, for more compositions and for higher pressures.

The pressure range is currently being extended in two ways. The first method is to develop massive high-pressure apparatuses, some capable of conducting $X$-ray analysis of samples while they are within the apparatus at high pressures and temperatures. The other method involves development of the much smaller diamond-anvil high-pressure cell. A sample squeezed between two diamond anvils is heated by a laser beam, and a variety of optical, X-ray, and spectroscopic measurements can be made in situ. With this device, reconnaissance studies of conditions down to the mantle-core boundary are under way.

Until all phase diagrams are determined or calculated, Bowen's philosophy of deducing "not-impossible" phase diagrams, by interpolation or extrapolation, or by the use of germane systems modelling for silicate systems, continues to be a valuable approach. The approach becomes more rigorous with advances in thermodynamic calculations involving reactions among solids, vapors and liquids at high pressures. Calculations have been hampered by inadequate thermochemical data.

The combination of calorimetry and experimental petrology is developing into a powerful approach, made possible through the recent design of new methods for applying high-temperature solution-calorimetry to the refractory rock-forming minerals. Equilibrium relations among minerals may be defined with a clarity impossible in the single approach of either thermochemistry or experiment. Thermochemical data for silicate liquids are less reliable, but research programs are under way to determine the hightemperature heat-contents of silicate liquids by calorimetry. The thermodynamic data obtained will improve calculated estimates of depths and temperatures at which magmas equilibrated with stipulated source materials.

\section{Experimental Approaches}

Current experimental approaches to investigation of petrological processes include the following:

1. determination of the phase relationships for individual minerals in simple synthetic systems,

2. determination of the phase relationships of mineral assemblages representing simplified rocks,

3. determination of the phase relationships for all compositions in ternary or quaternary systems that include the rock-forming minerals,

4. determination of the phase relationships of whole rocks,

5. determination of the phase relationships of possible source rocks and derivative magma compositions,

6. determination of the phase relationships in genetically related rock series,

7. determination of reaction rates,

8. crystallization of melts at various cooling rates,

9. any of the above in the presence of controlled amounts of (or buffered) $\mathrm{H}_{2} \mathrm{O}, \mathrm{CO}_{2}, \mathrm{O}_{2}$ and other volatile components,

10. determination of diffusion rates, e.g. of water through a partially melted assemblage, and

11. determination of physical properties of minerals and mineral assemblages in phase fields.
In all of these approaches, measurement of mineral compositions and the distribution coefficients of major elements has become routine with the recent development of energy-dispersive electron microprobes. Much current effort is being directed towards the distribution of minor and trace elements, including rare earth elements and isotopes.

\section{Applications}

Experimental results from these many approaches have applications to geophysical, petrological and geological processes extending from the earth's deep mantle to the surface. For example, the results of experimental petrology have been influential in testing models for the derivation of lunar anorthositic highland rocks and mare basalts from possible mantle source rocks within the moon. It is impossible to survey the complete range of results in the space of this article, but I have selected a few more examples.

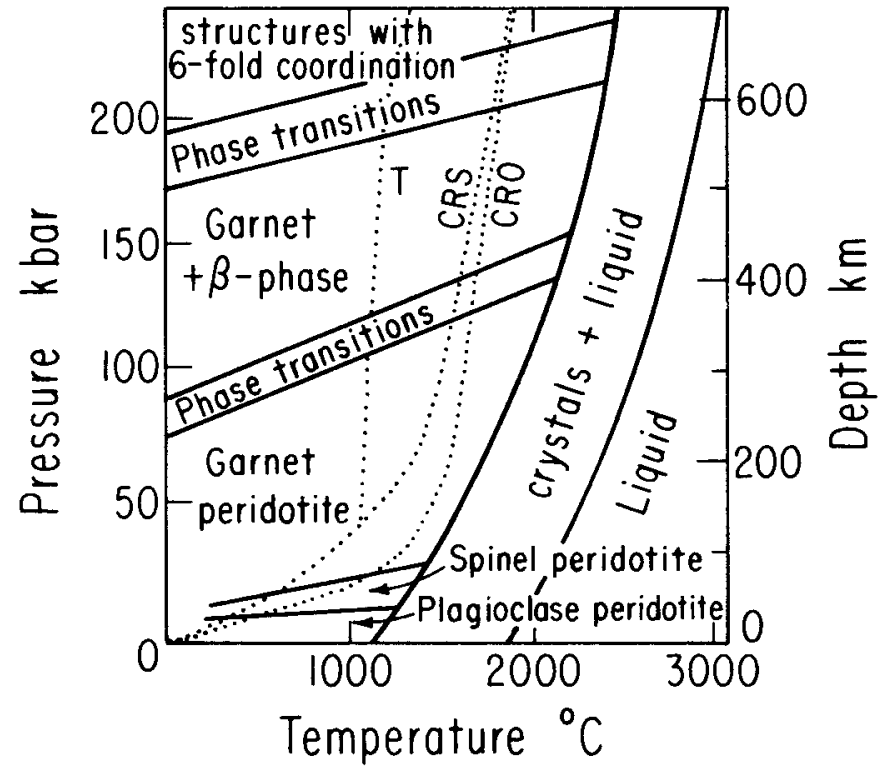

Figure 1. Phase diagram for mantle peridotite, largely schematic. Dotted lines are estimated geotherms (see Wyllie, 1971, p. 132).

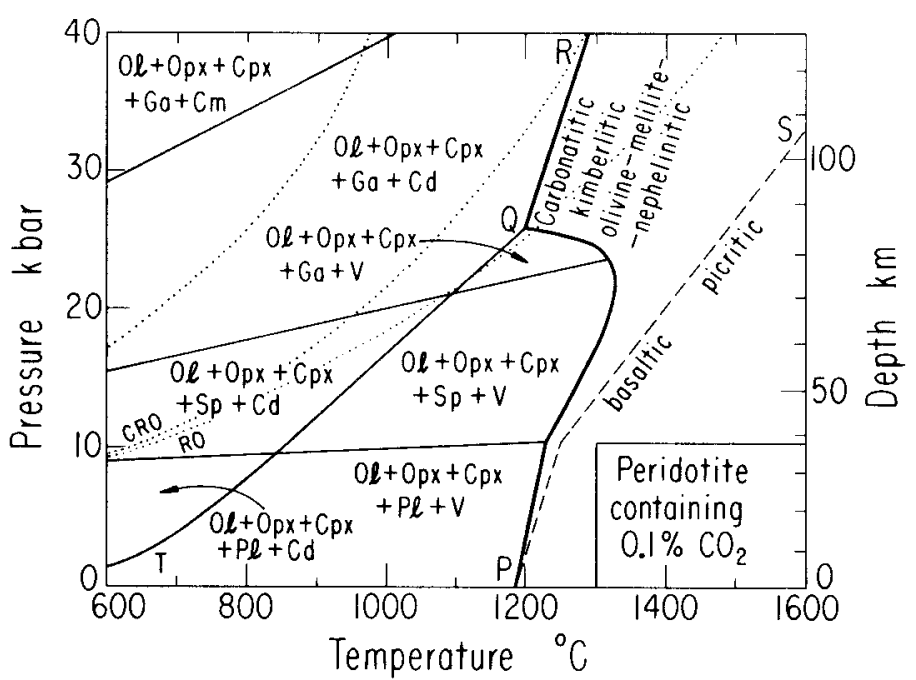

Figure 2. Phase diagram for a mantle peridotite, and effect of $\mathrm{CO}_{2}$, partly schematic (see Wyllie, 1971, Ch. 6; Wyllie, $1977 a)$. 


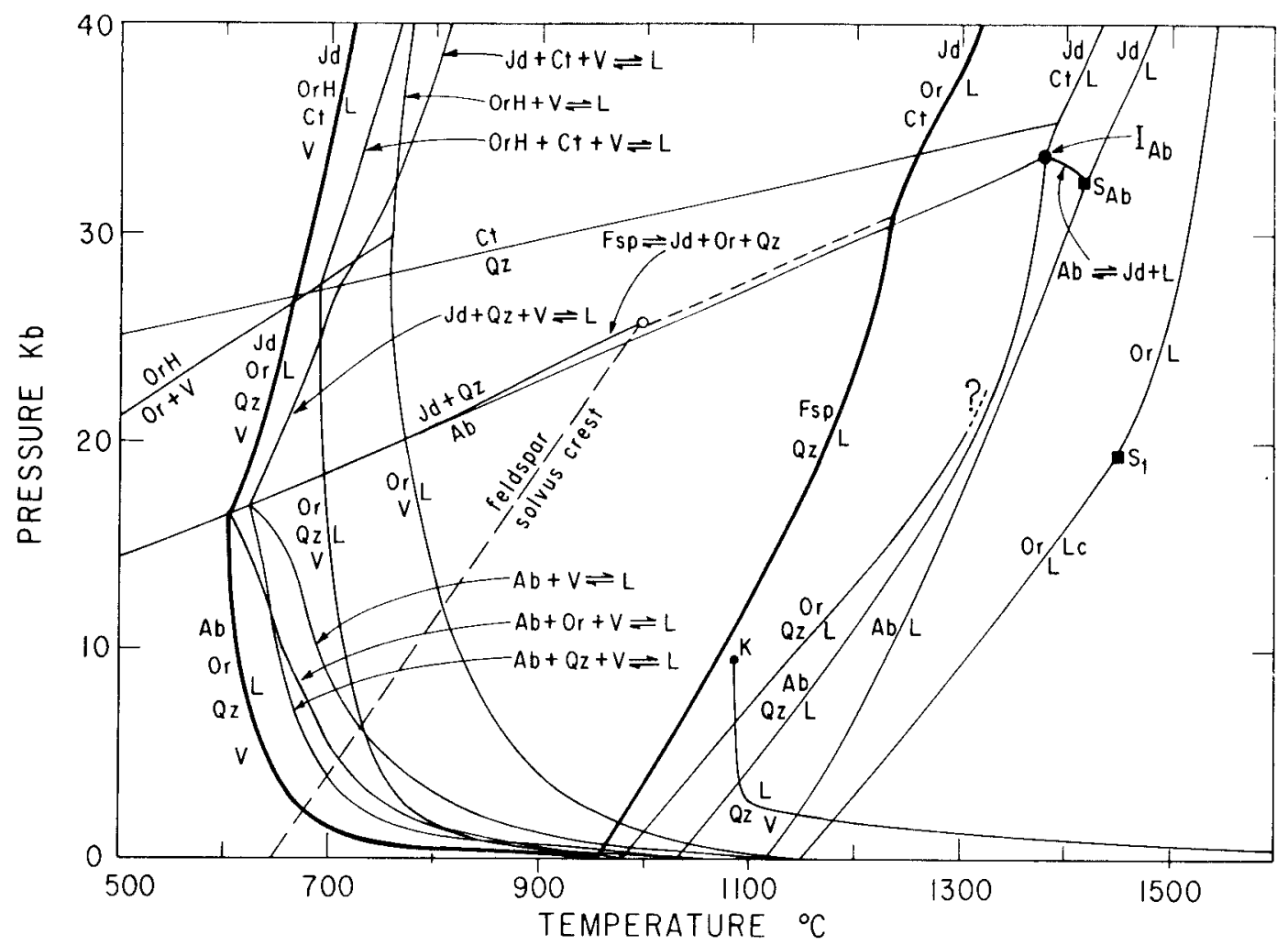

Figure 3. The system $\mathrm{NaAlSi}_{3} \mathrm{O}_{8}-\mathrm{KalSi}_{3} \mathrm{O}_{8}-\mathrm{SiO}_{2}-\mathrm{H}_{2} \mathrm{O}$, the granite system, through crustal to mantle pressures (Huang and Wyllie, 1975).

We live on a thin granitic continent overlying peridotite. Figure 1 is a largely schematic phase diagram for peridotite, showing subsolidus phase fields, phase transitions, and a wide melting interval from which basaltic magmas are derived, provided that the normal temperatures represented by the dotted lines are increased. Routine laboratory experiments probe to depths equivalent to $100 \mathrm{~km}$, but the new diamond-anvil cells now allow 'exploration' of phase transitions equivalent to $600 \mathrm{~km}$ depth.
The low-pressure part of Figure 1 is illustrated in Figure 2, together with the changes caused by the presence of a trace of $\mathrm{CO}_{2}$. Note that the assemblage of olivine plus two pyroxenes $(01+$ Opx $+\mathrm{Cpx})$ is divided into three facies with plagioclase (Pl), spinel ( $\mathrm{Sp}$ ), or garnet (Ga). Calibration of the compositions of coexisting minerals in terms of pressure and temperature, and application to the mineralogy of peridotite nodules carried to the surface in kimberlites or

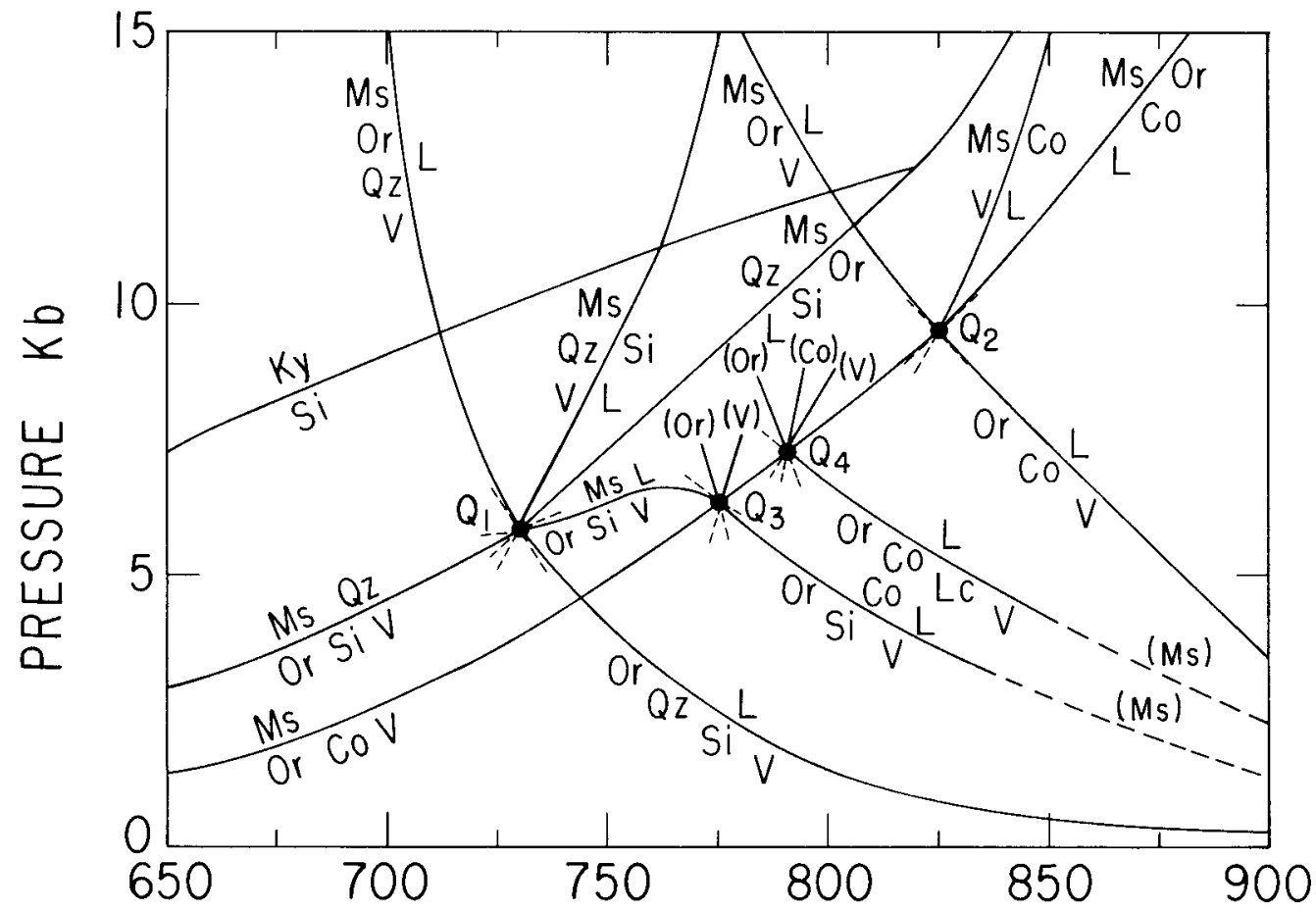

Figure 4. A simple petrogenetic grid, showing the dissociation and melling of muscovite, associated with quartz, orthoclase, and water vapor (Huang and Wyllie, 1974). 
basalts, has provided estimates of fossil geotherms existing in the mantle at the time of eruption. The dashed line PS is the peridotite solidus, which is lowered to PQR (heavy solid line) by the $\mathrm{CO}_{2}$. The large effect on the solidus temperature near $25 \mathrm{kbar}$ pressure is caused by the subsolidus carbonation reaction, TQ. Below this line, $\mathrm{CO}_{2}$ exists as free vapor, but above this line the $\mathrm{CO}_{2}$ reacts to produce dolomite $(\mathrm{Cd})$. Melting along QR then produces a trace of liquid very rich in carbonate.

The mineralogy of the crust is dominated by feldspars and quartz. Phase relationships for the granite system,

$$
\mathrm{NaAlSi}{ }_{3} \mathrm{O}_{8}-\mathrm{KAISi}_{3} \mathrm{O}_{8}-\mathrm{SiO}_{2}-\mathrm{H}_{2} \mathrm{O}\left(\mathrm{Ab}-\mathrm{Or}-\mathrm{Qz}-\mathrm{H}_{2} \mathrm{O}\right)
$$

are shown in Figure 3. There are four types of reactions. The feldspar solvus crest shows the temperature limit for the formation of perthites. Lines for jadeite (Jd) and coesite $(\mathrm{Ct})$ represent phase transitions where crustal minerals transform in to more dense minerals. The fusion curves for the minerals have positive slopes (dP/dT). The dramatic effect of dissolved $\mathrm{H}_{2} \mathrm{O}$ in lowering the melting temperatures is shown by the family of solidus curves with $V$ as a phase. Note that these change slope at invariant points where denser minerals are produced. By contrast, the effect of $\mathrm{CO}_{2}$ on the solidus temperature of peridotite, at pressures below the carbonation reaction is small (Fig. 2 ).

Crustal rocks contain hydrous minerals. Figure 4 shows univariant curves for the stability ranges and melting of muscovite, and of muscovite + quartz, with and without excess $\mathrm{H}_{2} \mathrm{O}$. These curves, together with (1) similar determinations for other hydrous minerals such as chlorite, biotite and amphibole, (2) decarbonation reactions such as $\mathrm{TQ}$ in Figure 2, and (3) solid-solid reactions or transitions such as kyanite-sillimanite $(\mathrm{Ky}-\mathrm{Si})$ in Figure 4, provide a petrogenetic

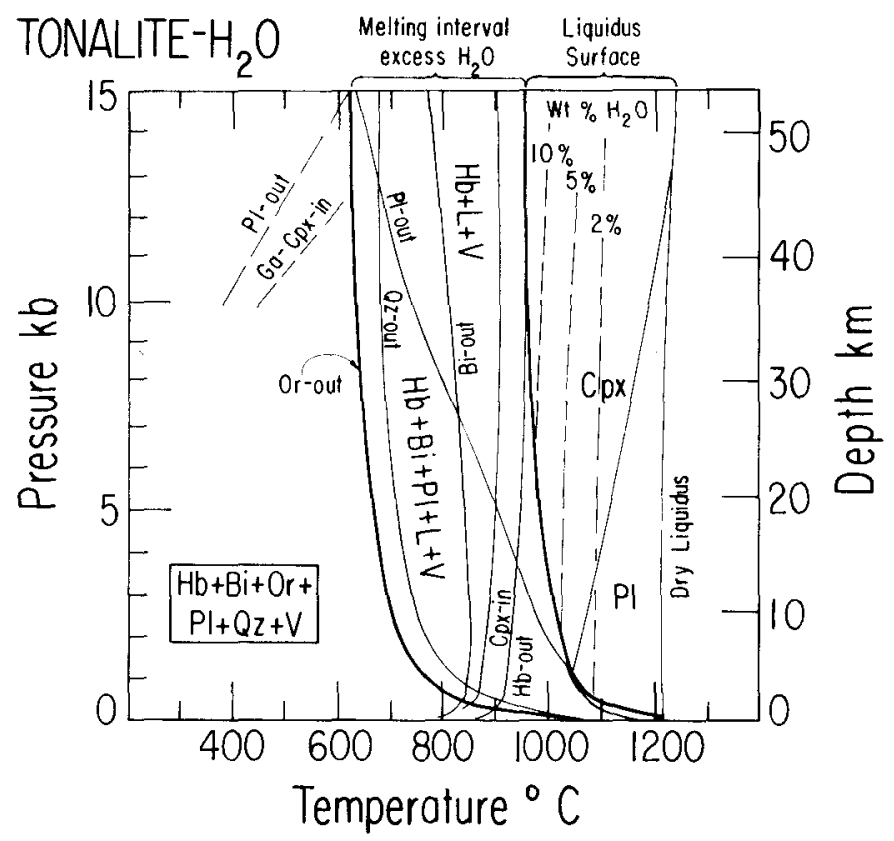

Figure 5. Phase diagram for tonalite with $\mathrm{H}_{2} \mathrm{O}$, partly schematic (Wyllie, 1977b).
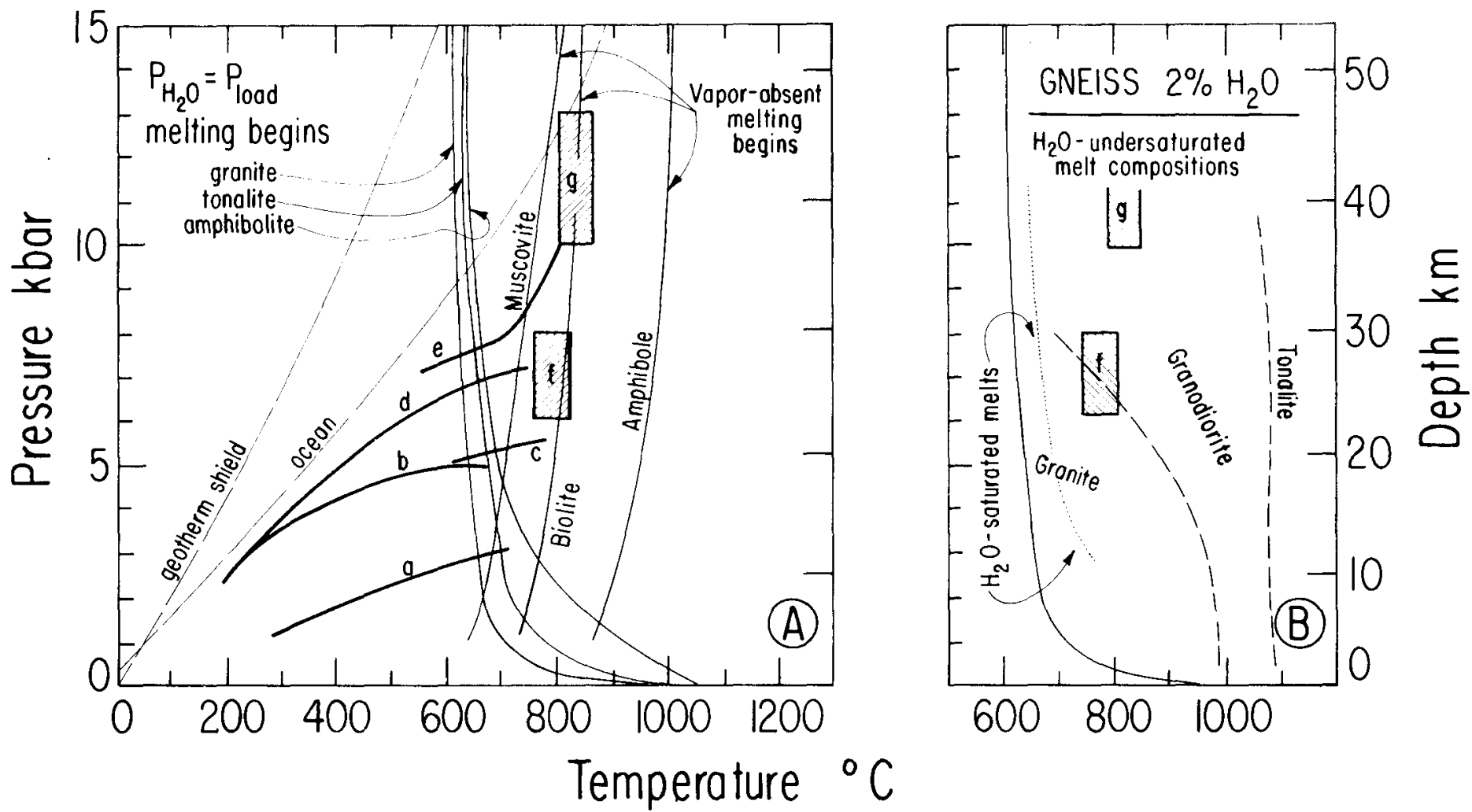

Figure 6A. Conditions for the melting of crustal rocks compared with depth-temperature paths for regional metamorphism ( $\left.a^{-} g\right)$. Estimated compositions of liquid formed in gneisses of dioritic composition (Wyllie, 1977b). 
grid, or the framework for estimating the depth-temperature history of metamorphic rocks. The melting curves place limits on the conditions for crustal anatexis.

A more direct approach to the study of anatexis involves melting whole rocks as shown for a tonalite in Figure 5. In the presence of aqueous pore fluid, the temperature at the beginning of melting is independent of the amount of $\mathrm{H}_{2} \mathrm{O}$. The liquidus temperature however, as shown by the contours on the liquidus surface, is very dependent on the total amount of $\mathrm{H}_{2} \mathrm{O}$ available.

Figure 6A compares curves for the beginning of melting of amphibolite, tonalite and granite in the presence of excess $\mathrm{H}_{2} \mathrm{O}$. They are not far separated, indicating that migmatites should form in most crustal rocks at similar depths. The heavy lines a to $e$ and the box $f$ represent depthtemperature paths estimated for different metamorphic terranes, based on petrogenetic grids (compare Fig. 4). The box $g$ represents depth-temperature calculated from element distribution among coexisting minerals. If there is no free pore fluid, melting then begins by the breakdown of a hydrous mineral, along one of the curves shown for muscovite, biotite, or amphibole. Vapor-absent melting of muscovite in a simple system is shown in Figure 4. Figure 6B shows the estimated ranges of liquid compositions produced from a dioritic gneiss with the composition of the average continental crust, and a generous allowance of $2 \%$ pore water. Note that in order to produce a liquid of tonalite composition, the temperature must exceed the dashed line corresponding to the $2 \%$ liquidus contour in Figure 5. According to Figure 6, the normal product of regional metamorphism is interstitial granite liquid, grading into granodiorite with increasing temperature or depth, but estimated metamorphic temperatures do not appear to reach levels required to generate tonalite liquids.

\section{The Future}

Exploration in experimental petrology has established the main effects of pressure, temperature, and water content on mineral stabilities and fusion or crystallization sequences.
The influences of $\mathrm{CO}_{2}$ and oxygen fugacity are becoming better evaluated. Improvements in thermodynamic calculations are supplementing the experimental results, but I think it will be a long time before calculations can replace the need for experiments. The marked effect of $\mathrm{CO}_{2}$ on melting shown in Figure 2 was not predicted, but discovered by experimental exploration only in 1975.

In addition to further exploration and expansion to higher pressures, many reconnaissance studies need to be completed in detail, including the measurement of phase compositions. The study of dynamic systems, reaction rates, and physical properties has barely begun.

A notable feature of experimental petrology is its increasing interdependence with geophysics, geochemistry and field petrology, as well as thermodynamic theory. Experimental petrology may be considered as the Materials Science of the Geophysical Sciences.

\section{References}

Huang, W.L., and Wyllie, P.J., 1974, Melting relations of muscovite with quartz and sanidine in the system $\mathrm{K}_{2} \mathrm{O}$ $\mathrm{Al}_{2} \mathrm{O}_{3}-\mathrm{SiO}_{2}-\mathrm{H}_{2} \mathrm{O}$ to 30 kilobars and an outline of paragonite melting relations: Am. J. Sci., v. 274 , p. 378395.

Huang, W.L., and Wyllie, P.J., 1975, Melting reactions in the system $\mathrm{NaAlSi}_{3} \mathrm{O}_{8}-\mathrm{KAISi}_{3} \mathrm{O}_{8}-\mathrm{SiO}_{2}$ to 35 kilobars, dry and with water: J. Geol., v. 83, p. 737-748.

Wyllie, P.J., 1971, The Dynamic Earth: a Textbook in Geosciences: New York, John Wiley \& Sons, 416 p.

Wyllie, P.J., 1977a, Mantle fluid compositions buffered by carbonates in peridotite- $\mathrm{CO}_{2}-\mathrm{H}_{2} \mathrm{O}$ : J. Geol., v. 85, p. 187-207.

Wyllie, P.J., 1977b, Crustal anatexis: an experimental review: Tectonophysics, v. 43, p. 41-71.

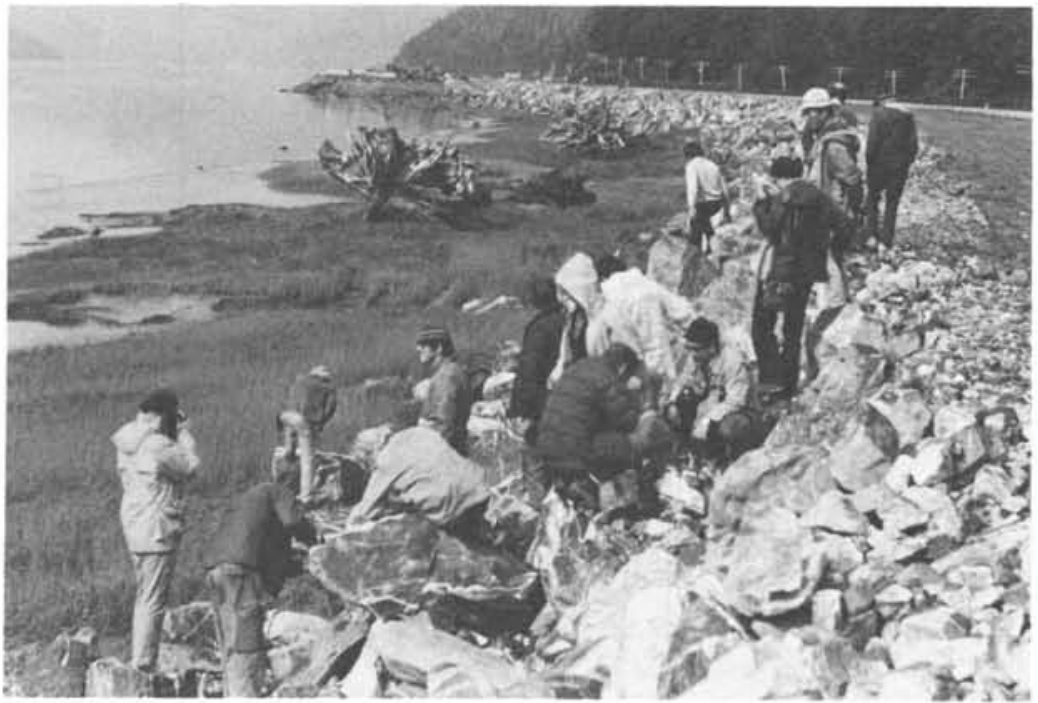

Peter Wyllie (extreme left) leads a group to seek high pressures and temperatures in the field, Cordillera of North America.

ABOUT THE AUTHOR: Recently named the Homer J. Livingstone Professor at the University of Chicago, USA, Professor Peter Wyllie has gained a world-wide reputation as editor (Journal of Geology; Springer-Verlag Series) and as author of, among others, the noteworthy introduction to new global geology, The Way the Earth Works (1976). Aside from his active involvement in IUGS, he has played a key role in some of the most stimulating symposia presented at the last two International Geological Congresses. Professor Wyllie has just been appointed President of the Mineralogical Society of America. 